\title{
RELATION BETWEEN IONIC COUPLING AND MORPHOLOGY OF ESTABLISHED CELLS IN CULTURE
}

\author{
D. F. HÜLSER and D, J. WEBB \\ Max-Planck-Institut fïr Virusforschung, Abt. Physikalische Biologie, 74 Tübingen, BRD
}

\begin{abstract}
SUMMARY
Ionic coupling was found in all investigated fibroblastoid cells of 7 permanent cell lines in culture, whereas in 7 epithelioid cell lines no coupling could be detected. These established lines consisted of cells of normal or malignant origin as well as cells that were able to, or failed to, produce tumors, but the only relation with ionic coupling appeared to be morphology. The ionic coupling between fibroblastoid cells was unaffected by the presence of fetal calf serum instead of calf serum; culturing in media conditioned by non-coupled cells; variation of the potential difference and phase of the cell cycle. Coupled cells could be depolarized by decreasing the bicarbonate concentration in the media; non-coupled cells were unaffected.
\end{abstract}

The existence of low-resistance junctions between non-excitable cells in culture is well documented for cells of the same $[2,6,13$, $14,17,18,25]$ as well as of different types $[2,14,24]$. Initial findings of Loewenstein \& Kanno [22] with liver and hepatomas in situ revealed a difference between normal cells which showed ionic coupling and malignant cells which were not coupled. Subsequently, a number of in vivo and in vitro cell lines were described which were both malignant and ionically coupled $[5,6,13,17,18,19$, 39]. Therefore, it was proposed [2] that a distinction could be made in another way: non-coupled cells should be potentially cancerous whereas coupled cells could be either normal or malignant.

Examples are presented in which the existence of low-resistance junctions seems to be associated with those cells in permanent culture that have fibroblastoid morphology rather than with epithelioid cells which are not ionically coupled. Further- more, we show that the lack of ionic coupling does not appear to be related to malignant growth. Experiments were also performed to examine the relationship between ionic coupling and membrane resistance, potential difference, culture conditions and cell cycle phase.

\section{MATERIALS AND METHODS}

\section{Cell cultures}

The permanent cell lines ('established cell lines') are described in the results (table 2). The RE-cells are derived from spontaneously transformed embryonic rat cells by Dr W. Frank in this department. Cell lines 2-5 were established in this department between 1967 and 1969 by Professor H. Friedrich-Freksa who also kindly provided the HeLa and KB cells. We selected cell line 8 from cell line 1 , by passaging the cells without the use of trypsin but by shaking the cells off the monolayer in fresh medium. The 3T3 cells were obtained from Professor W. Schäfer, MPI für Virusforschung, Biologisch-Medizinische Abteilung, Tübingen. The BHK lines $10-12$ were kindly provided by Dr W. Schwöbel, Bundesforschungsanstalt für Viruskrankheiten der Tiere, Tübingen. Cell lines 13 and 14 were derived from transplanted rat tumors by $\mathrm{Dr}$ M. F. Rajewsky in this department. 
Table 1. Salt concentrations ( $m M$ ) of the media and solutions

In every case $2.4 \mathrm{mM} \mathrm{Ca}^{2+}, 1 \mathrm{mM} \mathrm{Mg}^{2+}, 1 \mathrm{mM}$ $\mathrm{SO}_{4}{ }^{2-}$ and $1 \mathrm{mM} \mathrm{HPO}{ }_{4}{ }^{2-}$ were present

\begin{tabular}{|c|c|c|c|c|}
\hline \multirow[b]{2}{*}{ Ion } & \multicolumn{4}{|l|}{ Medium } \\
\hline & $\begin{array}{l}\text { Eagle- } \\
\text { Dulbecco }\end{array}$ & HEPES & High $\mathbf{K}^{+}$ & $\begin{array}{l}\text { Bicar- } \\
\text { bonate- } \\
\text { free salt- } \\
\text { glucose } \\
\text { sol. }\end{array}$ \\
\hline $\mathbf{K}^{+}$ & 5.4 & 5.4 & 60 & 5.4 \\
\hline $\mathrm{Na}^{+}$ & 154 & 116 & 91 & 110 \\
\hline $\mathrm{Cl}^{-}$ & 118 & 118 & 107 & 118 \\
\hline $\mathrm{HCO}_{3}^{-}$ & 44 & 6 & 44 & 0 \\
\hline Glucose & 27 & 27 & 80 & 27 \\
\hline Hepes & 0 & 30 & 0 & 30 \\
\hline
\end{tabular}

The cells were cultured at $37^{\circ} \mathrm{C}$ in a modified Eagle-Dulbecco medium [12] with $10 \%$ calf serum, under an atmosphere of $5 \% \mathrm{CO}_{2}$ in air, at $\mathrm{pH} 7.4$. The salt concentrations of the different media used for these investigations arc shown in table 1. Cells cultured in HEPES-buffered medium were kept without $\mathrm{CO}_{2}$. The stock culture media were changed for fresh every 2 days. The experiments were performed at room temperature with and without medium exchange.

The cells were passaged at the end of the log phase of growth by treating the monolayer with trypsin at $37^{\circ} \mathrm{C}(0.25 \%$ trypsin in $\mathrm{Ca}-\mathrm{Mg}$-free isotonic phosphate-buffered salt solution). After washing in modified Eagle-Dulbecco medium, the cells were seeded into glass bottles for stock cultures and in plastic Petri dishes (Falcon or Greiner-Nürtingen, $50 \mathrm{~mm}$ diameter; $1 \times 10^{5}$ cells $/$ dish; $5 \mathrm{ml}$ medium). For some experiments the cells were partially synchronised by blocking DNA synthesis with $5 \times 10^{-4} \mathrm{M}$ of hydroxyurea or metaphase arrest with $1 \times 10^{-7} \mathrm{M}$ of Colcemid, each for $10 \mathrm{~h}$, and subsequent reversion of the blocks by medium exchange.

Tumorigenicity tests were made with 10-day-old rats of the strain from which the cells had originated. $1 \times 10^{\mathrm{a}}$ viable cells (trypan-blue exclusion) in $0.5 \mathrm{ml}$ medium without serum were injected subcutaneously on the back, in some cases the dose was given twice at one time.

\section{Electrical measurements}

A schematic drawing of the electrical set-up is shown in fig. 1. The microelectrode measurements were made with Ling-Gerard electrodes filled with $3 \mathbf{M}$ $\mathrm{KCl}$ and $2 \mathrm{mM} \mathrm{K}$-citrate (resistance 30-50 $\mathrm{M} \Omega$, tip potential $\leqslant 5 \mathrm{mV}$ ). The recording electrodes were connected to a negative capacitance electrometer (Keithley 605). The current electrodes were supplied with 6 rectangular pulses/min from a modified Tektronix generator $(601 / 161 / 162)$. Shorter pulses

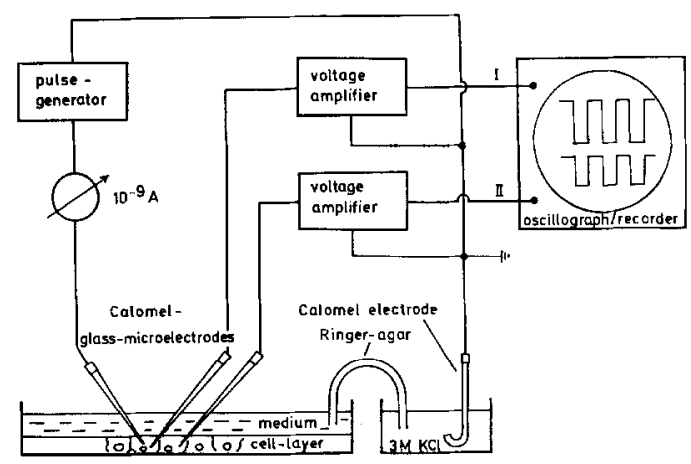

Fig. 1. Scheme of the electrical set-up. Pulses of constant current of about $20 \mathrm{nA}$ were injected into a cell with a glass microelectrode. The resulting voltage changes were recorded in the same and in surrounding cells with two recording electrodes. The electrical circuit was closed by an indifferent calomel electrode which was connected to the medium by a Ringer-agar bridge. After amplification, the measurements were observed at an oscillograph or recorded by a pen recorder.

for better time resolution were supplied via a photon coupled isolator as described by Baird [3]. The differentiation of a ramp signal by an RC combination (electrode resistance and constant capacitor in the negative capacitance electrometer) allowed the determination of the electrode resistance by comparing the resulting square pulse with the pulses obtained with known resistors. This method could also be used for the estimation of the ohmic resistance of the membrane. With an electrode inserted in a cell, the membrane resistance is additive to the electrode resistance. Thus, the difference of the pulse height with an inserted electrode and the pulse height of the clectrode in the medium indicates the ohmic resistance of the membrane. This will be a slight underestimation as the electrode resistance decreases when the electrode is inserted into a cell. However, insertion of a current and a recording electrode and subsequent calculation of the resistances by current-voltage measurements or by the voltage dividing method resulted in the same values for the membrane resistance as with this single electrode method. Furthermore, this method allowed demonstration of a membrane capacitance, which was indicated by an increased rise time of the square pulse.

During the measurements, the culture dishes were observed with a phase-contrast microscope (Zeiss Standard RA) with a $40 x$ waler-immersion ubjective which was electrically insulated. For details see [16].

\section{RESULTS}

The investigated permanent cell lines can be divided into two morphologically different 

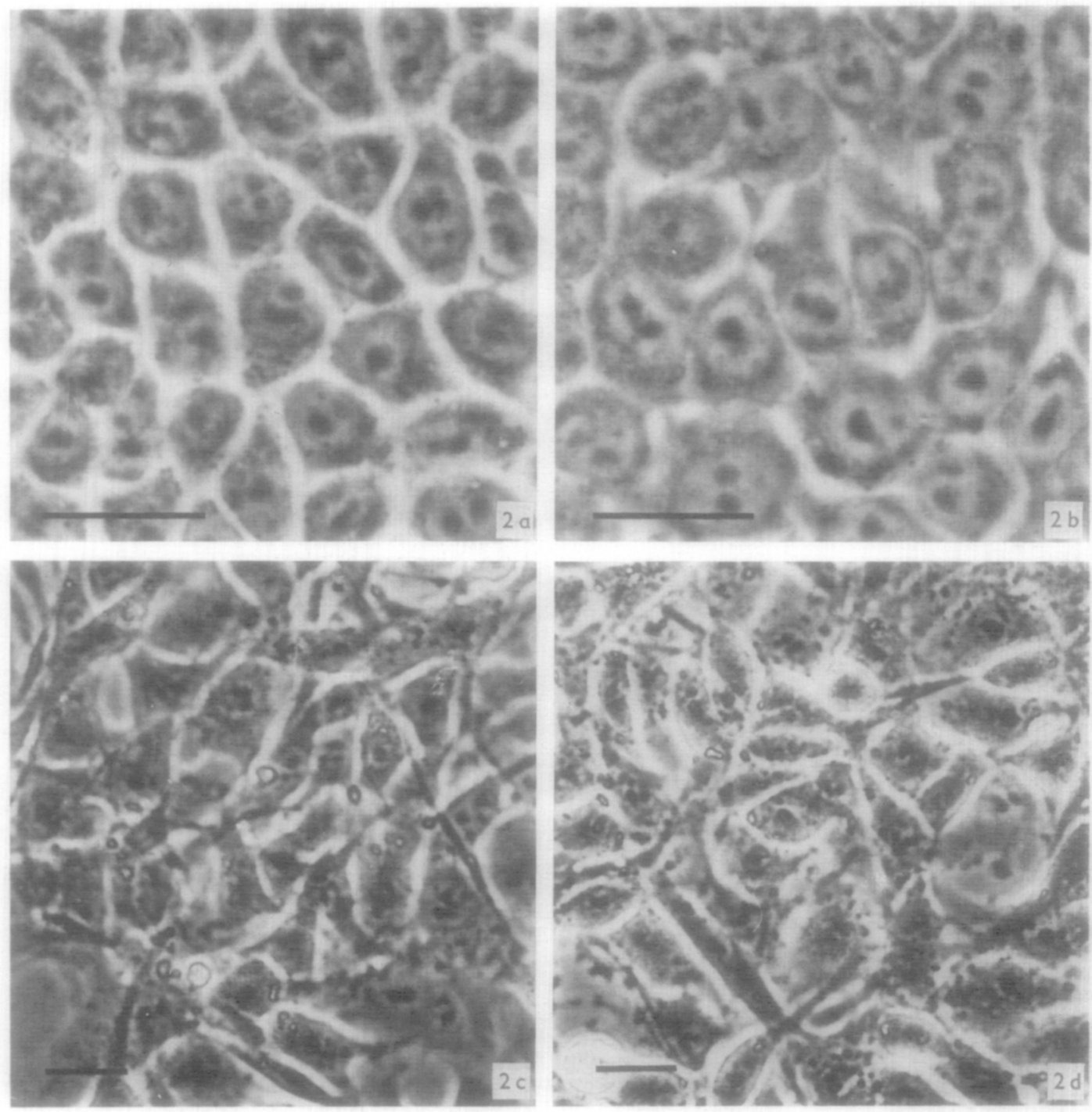

Fig. 2. 4 morphological representative cell lines: (a) epithelioid embryonic rat cells (RE); $(b)$ epithelioid embryonic hamster cells (HE 22667); (c) fibroblastoid embryonic rat cells (RE-F), selected from RE-cells; (d) ibroblastoid rat tumor cells (BICR/M1R-K). Bars: $25 \mu \mathrm{m}$.

classes: fibroblastoid cells and epithelioid cells. It is important that the cell morphology is determined when the cells have formed a confluent monolayer, since epithelioid cells sometimes appear fibroblastoid while they are isolated. Fig. 2 shows four representative cell lines, which illustrate what we considered to be epithelioid and fibroblastoid morphology. All of the cell lines within a class showed similar behaviour with respect to ionic coupling and, as far as investigated, to reduced bicarbonate concentration of the medium.

\section{Ionic coupling and cell morphology}

In table 2, the results of the experiments are summarized where ionic coupling in permanent cell cultures was investigated. As 
Table 2. Summarized results of the investigated cell-lines

The decision of whether cells were coupled or not was made after at least 50 measurements in different dishes from various preparations. In the case of $R E$ and BICR/M1R-K cells several hundred measurements have been carried out

\begin{tabular}{|c|c|c|c|c|c|}
\hline Cell line & Origin & $\begin{array}{l}\text { Morphology } \\
\text { when forming } \\
\text { a monolayer }\end{array}$ & $\begin{array}{l}\text { Ionic } \\
\text { coupling }\end{array}$ & $\begin{array}{l}\text { Tumor- } \\
\text { igenicity }\end{array}$ & [References] \\
\hline $1 \operatorname{RE}(6267)$ & $\begin{array}{l}\text { Rat embryo } \\
\text { (Sprague Dawley) }\end{array}$ & Epithelioid & - & - & \\
\hline $2 \mathrm{ME}(7 \mathrm{769})$ & $\begin{array}{l}\text { Mouse embryo } \\
\text { (BALB) }\end{array}$ & Epithelioid $^{c}$ & - & - & [10] \\
\hline $3 \mathrm{HE}(22667)$ & Hamster embryo & Epithelioid & - & $d$ & \\
\hline $4 \mathrm{HE}(21268)$ & Hamster embryo & Epithelioid & - & $d$ & \\
\hline 5 HEBP (131 267) & $\begin{array}{l}\text { Hamster embryo } \\
\text { benzpyrene- } \\
\text { transformed }\end{array}$ & Epithelioid $^{c}$ & - & $d$ & \\
\hline $6 \mathrm{HeLa}$ & $\begin{array}{l}\text { Human cervix } \\
\text { carcinoma }\end{array}$ & Epithelioid & -- & + & [40] \\
\hline $7 \mathrm{~KB}$ & $\begin{array}{l}\text { Human epidermoid } \\
\text { carcinoma of } \\
\text { the nasopharynx }\end{array}$ & Epithelioid & - & + & [4] \\
\hline 8 RE-F (1 272) & $\begin{array}{l}\text { Rat embryo } \\
\text { (Sprague Dawley, } \\
\text { selected from RE) }\end{array}$ & Fibroblastoid & + & - & \\
\hline $93 \mathrm{~T} 3$ & Mouse embryo & Fibroblastoid & + & - & [1] \\
\hline 10 BHK-21 & $\begin{array}{l}\text { Baby-hamster } \\
\text { kidney }\end{array}$ & Fibroblastoid & + & + & [36] \\
\hline $11 \mathrm{BHK}-21 / \mathrm{SV}^{a}$ & $\begin{array}{l}\text { Baby-hamsler } \\
\text { kidney }\end{array}$ & Fibroblastoid & + & t & [36] \\
\hline $12 \mathrm{BHK}-21 / \mathrm{SVf}^{b}$ & $\begin{array}{l}\text { Baby-hamster } \\
\text { kidney }\end{array}$ & Fibroblastoid & + & t & [36] \\
\hline $13 \mathrm{BICR} / \mathrm{M} 1 \mathrm{R}-\mathrm{K}$ & $\begin{array}{l}\text { Transplanted rat } \\
\text { mammary tumour } \\
\text { (Marshall) }\end{array}$ & Fibroblastoid & + & + & \\
\hline $14 \mathrm{RN}$ & $\begin{array}{l}\text { Transplanted rat } \\
\text { neurinoma (BD IX) }\end{array}$ & Fibroblastoid & + & + & {$[30]$} \\
\hline
\end{tabular}

${ }^{a} 1$ year persistent infection with Sindbis virus [37].

${ }^{b} 1$ year persistent infection with Sindbis virus eliminated by anti-Sindbis-bovine serum [37].

${ }^{c}$ These cells were more rounded than the other epithelioid cell lines.

a Not tested.

can be seen, there is no difference in the detection of ionic coupling, whether the cells are of normal or of malignant origin or whether they are transformed in vitro as long as they are of fibroblastoid appearance. The rounded mitotic cells of these lines were also ionically coupled to other cells of the monolayer. On the other hand, no ionic coupling could be detected with the permanent epithelioid cells, again regardless of the origin of the cells.

Fig. 3 shows representative oscilloscope tracings of the current pulses and the resulting voltage deflections of coupled BICR/ M1R-K cells and of non-coupled HeLa cells. The communication ratio $V_{\mathrm{II}} / V_{\mathrm{I}}$, as de- 
fined by Loewenstein \& Kanno [22], namely the ratio of the voltage change at constant current pulses in the coupled cell to the voltage change in the cell containing both recording and stimulating electrodes, could vary between 0.3 and 1.0 but was independent of the cell density of the monolayer. Over a distance of more than 10 cells, the communication ratio was frequently found to be as high as between neighbouring cells. Owing to the long filaments of the fibroblastoid cells, it is often difficult to determine whether cells are actually separated by other cells. For these reasons we have only indicated whether cells were ionically coupled or not, disregarding a communication ratio. This does not imply that all lines of fibroblastoid cells are coupled to the same degree. The communication ratio for $3 \mathrm{~T} 3$ cells, for instance, was always lower than that for BICR/MIR-K cells.

As can be seen from table 2, no ionic coupling is indicated for the epithelioid cells, but sometimes slight coupling $\left(V_{\mathrm{II}} / V_{\mathrm{I}} \sim 0.03\right)$ appeared between neighbouring cells several seconds to minutes after insertion of the electrodes. This coupling was considered to be an artifact, since at the same time one or more small blebs could be seen budding from impaled cells, as is demonstrated for RE-cells in fig. 4. These blebs may link the cells ionically. At the same time, the resistance and the capacitance of the membrane increased significantly (see fig. $5 f, \mathrm{~g}$ ), of ten together with an increase in the potential difference.

Such cells finally burst and the potential difference dropped to zero. At this time the resistance measurement just indicated the electrode resistance and no capacitance. In all cases where the potential difference, membrane resistance and capacitance remained stable and the impaled cells appeared in good condition with no blebs being found,

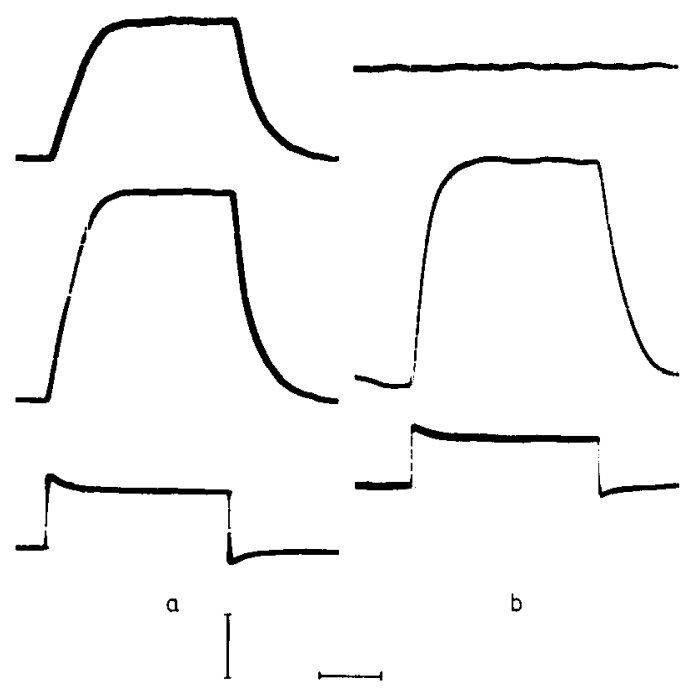

Fig. 3. (a) BICR/M1R-K cells: oscilloscope tracings of a current pulse (lower trace) and the resulting voltage deflections in the cell with the current electrode (middle) and in a coupled cell (upper). Vertical bar, $50 \mathrm{nA}$ or $25 \mathrm{mV}$; horizontal bar $20 \mathrm{msec}$. (b) HeLa cells: same experiment as in (a). Note that no current spreads to the neighbouring cell. Vertical bar, $10 \mathrm{nA}$ or $25 \mathrm{mV}$; horizontal bar, $20 \mathrm{msec}$.

coupling was never detected between epithelioid cells.

\section{Ionic coupling and membrane resistance}

Fig. 5 shows some representative measurements of resistance and capacitance of cell membranes. These measurements were performed with one electrode only to reduce the possibility of cell damage which may occur by the insertion of two electrodes. The pulse height in fig. $5 a$ represents the electrode resistancc in Eaglc-Dulbecco medium. Fig. 5( $b$ and $c$ ) shows the situation with the electrode inserted into a fibroblastoid cell (BICR/ M1R-K), 15 and $60 \mathrm{sec}$ after impalement. The increase in the pulse height indicates the cell membrane resistance, since electrode resistance and membrane resistance are mcasured in series. The slight change in the rise time is due to the membrane capacitance. Fig. $5 d$ shows the electrode resistance after withdrawing the electrode from the cell. 

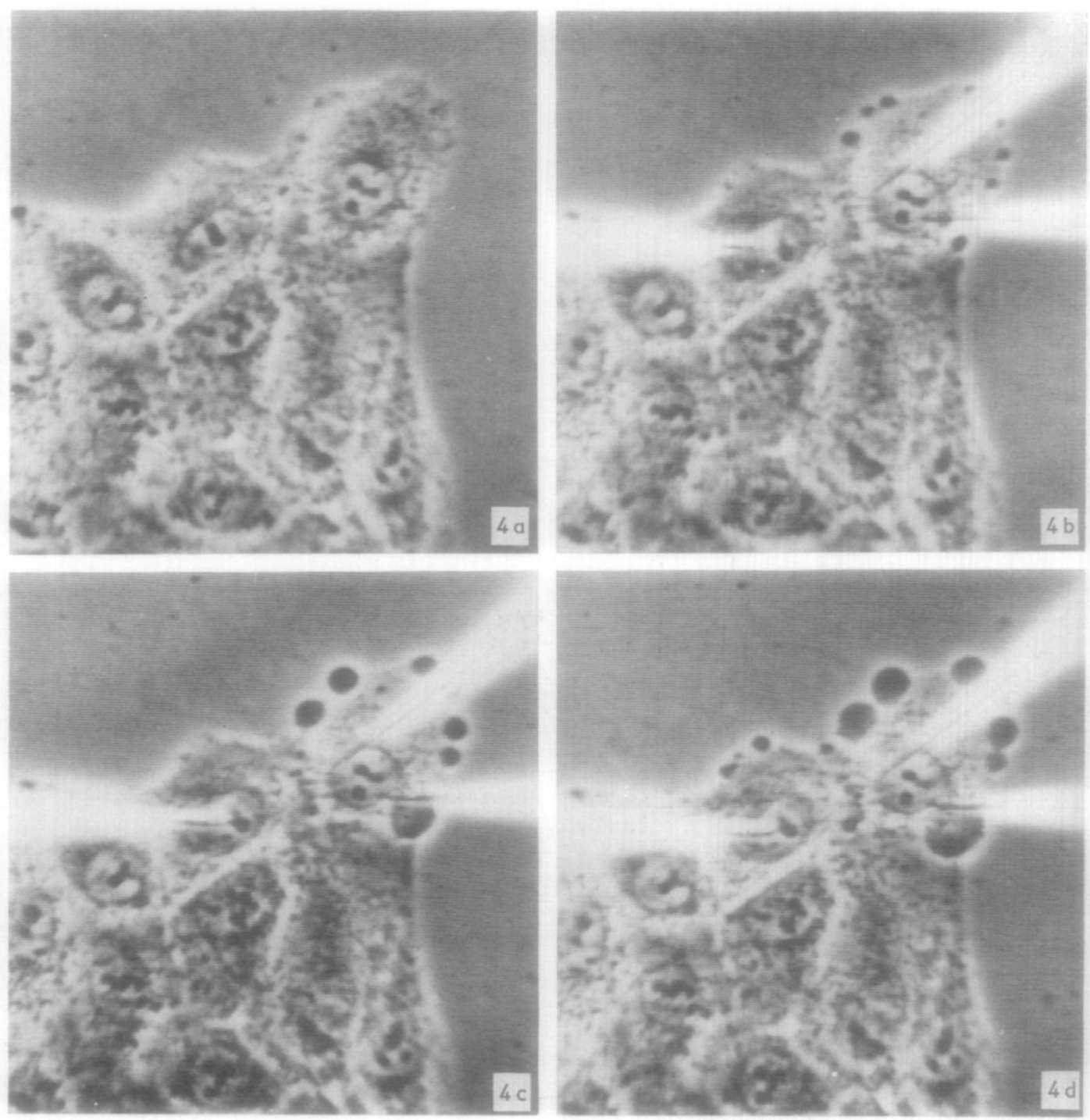

Fig. 4. Appearance of blebs after impalement of RE cells. The cell impaled with two electrodes first releases the blebs which may link the cells ionically. Soon after, the second cell with only one inserted electrode releases blebs. All four pictures were taken within 2 min from a television screen.

Fig. $5(e-h)$ demonstrates the situation in a non-coupled cell (HeLa). The ohmic membrane resistance is considerably higher and the membrane capacitance is very similar to that of the coupled cell, as can be seen from the $15 \mathrm{sec}$ reading. After $60 \mathrm{sec}$, however, when blebs had already appeared, not only had the membrane resistance increased but so also had the membrane capacitance. For purposes of comparison, fig. $5 i$ shows the pulse height of a known resistor of $100 \mathrm{M} \Omega$ while fig. $5 k$ shows the same resistor with a capacitor of $15 \mathrm{pF}$ in parallel, which increases the rise time in a way similar to that of the blebs in the non-coupled cell shown in fig. $5 g$. 

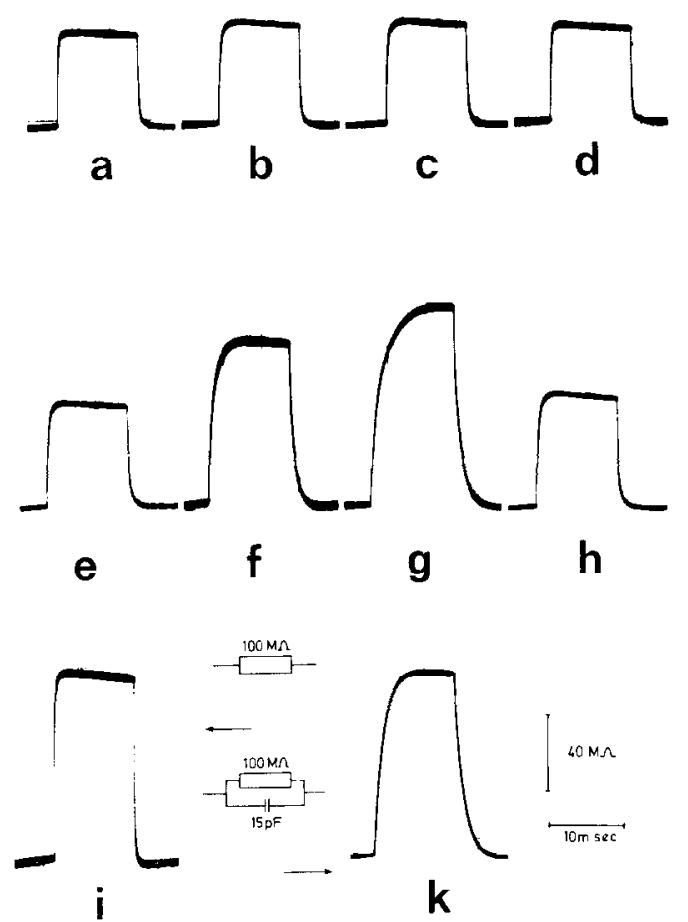

Fig. 5. Membrane resistance measurements in monolayer cells by the differentiation method using a single electrode. Resistance of $(a)$ electrode in medium; (b) electrode and cell membrane $15 \mathrm{sec}$ after insertion into a BICR/M1R-K cell; $c$, same as $(b), 60 \mathrm{sec}$ after insertion; $d$, resistance of electrode after withdrawal from cell; $e-h$, same as $(a)-(d)$, for HeLa cells; $i$, $100 \mathrm{M} \Omega$ resistor; $k, 100 \mathrm{M} \Omega$ resistor with a $15 \mathrm{pF}$ capacitor in parallel.

The lower membrane resistance of a fibroblastoid cell in a monolayer as compared with an epithelioid cell in a monolayer is further indication of the coupling of these fibroblastoid cells. In table 3 , the values for the membrane resistance of two coupled and two non-coupled cell lines are summarized for isolated and monolayer cells. These measurements were made with the differentiation method using the negative capacitance electrometer. Isolated cells of both coupled and non-coupled cells show a similar membrane resistance of about $13 \mathrm{M} \Omega$, which may vary with cell size. When the resistance of cells in a monolayer is measured, non-coupled cells have a re-
Table 3. Ohmic membrane resistances \pm S.E. of isolated and monolayer cells with the number of measurements in parentheses

\begin{tabular}{llr}
\hline \multirow{2}{*}{ Cell line } & \multicolumn{2}{c}{ Membrane resistance [M $[\mathrm{M}]$} \\
\cline { 2 - 3 } & Isolated cells & Monolayer cells \\
\hline RE (6 267) & $10.96 \pm 0.45(106)$ & $11.62 \pm 0.39(65)$ \\
HeLa & $16.61 \pm 0.78(38)$ & $16.33 \pm 0.71(67)$ \\
3T3 & $10.30 \pm 0.49(53)$ & $6.31 \pm 0.36(71)$ \\
BICR/M1R-K & $13.16 \pm 0.64(71)$ & $4.46 \pm 0.14(39)$ \\
\hline
\end{tabular}

sistance of the same order as when isolated, whereas the measured ohmic resistance of coupled cells is quite low because of currentspreading through the cell monolayer.

\section{Ionic coupling and potential difference}

As already described [16], the potential difference (P.D.) of fibroblastoid cells was influenced by the concentration of bicarbonate, whereas the P.D. of epithelioid cells remained unaffected. This effect could also be seen with the investigated embryonic rat cells. The P.D. of fibroblastoid RE-F cells in normal medium was $49.1 \pm 0.61 \mathrm{mV}$ (M. \pm S.E.). After exchanging this medium against bicarbonate-free salt solution (see table 1), the cells depolarized to a P.D. of $28.9 \pm$ $0.41 \mathrm{mV}$. The epithelioid RE cells showed no significant reaction to this medium exchange $(52.3 \pm 1.35 \mathrm{mV}$ and $49.6 \pm 1.51 \mathrm{mV})$.

The coupling between fibroblastoid cells was not altered in a predominant direction, either during or after such a medium exchange or in cells cultured in HEPES medium (see table 1), as was found for BICR/M1R-K, $3 T 3$ and RE-F cells. Fig. 6 shows an experiment in which the medium was exchanged during the measurement of ionic coupling between BICR/M1R-K cells. Here, the pulse height changed in both cells in the same proportion and direction, so that no significant change of the communication ratio resulted. As can be clearly seen, smaller 


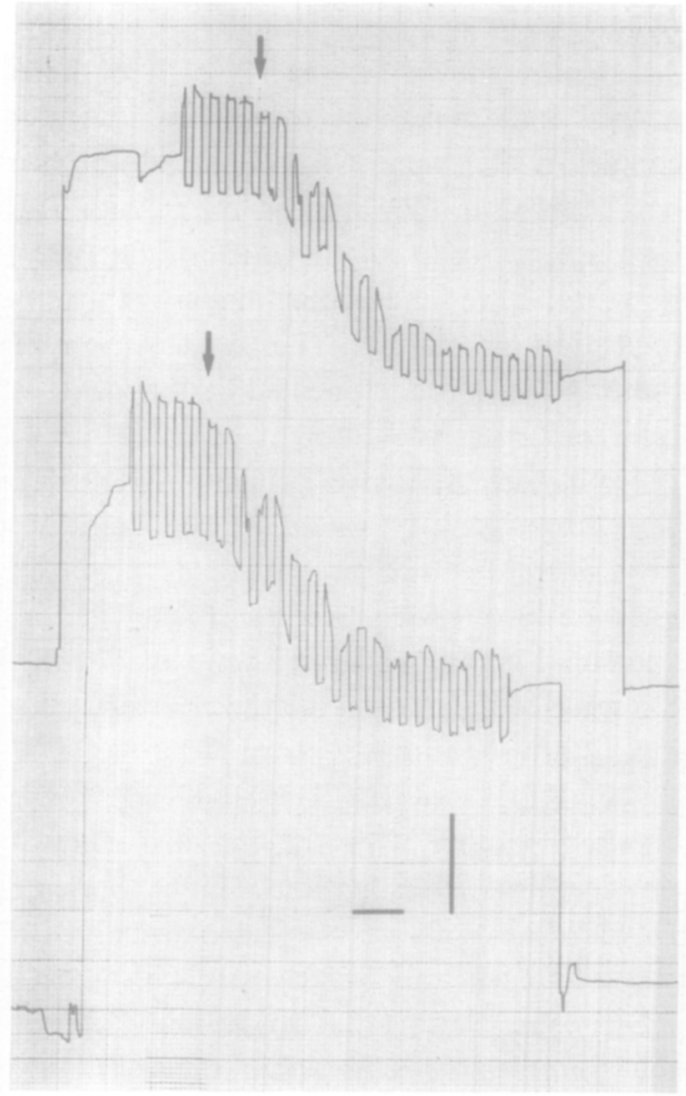

Fig. 6. Ionic coupling between BICR/MIR-K cells during depolarisation by bicarbonate-free salt-glucose solution. Lower line, (left) shows the P.D. line of the cell with both recording and current electrode inserted during presence of $44 \mathrm{mM} \mathrm{NaHCO}$ in the medium. The upper line is the P.D. line of a neighbouring cell coupled to the first one which can be seen by the pulses superimposed on the P.D. line. Arrows indicate where the medium was sucked off and the bicarbonate-free salt solution was run in (note that the upper line is $1 \mathrm{~min}$ ahead of the lower line; arrows indicate the same time). Both cells are depolarized in the same manner, and the pulses in both cells remain in the same proportion, indicating that in this experiment the communication ratio was not altered. Horizontal bar, $1 \mathrm{~min}$; vertical bar, $10 \mathrm{mV}$.

transient voltage changes, which are not due to the current pulses, are recorded in both cells simultaneously.

As long as the cells were isolated, we observed in both coupled and non-coupled cell lines a significant difference of the P.D.s between mitotic and interphase cells. Cells that rounded and commenced mitosis always had a P.D. of about $40-60 \mathrm{mV}$, whereas flat interphase cells had a low P.D. of about 10-20 mV. In cells of a confluent monolayer such a difference was not observed; the P.D. of all cells was of the same order as the P.D. of mitotic cells.

These findings suggested that the P.D. of the cells may be involved in the regulation of cell proliferation. We, therefore, exchanged the medium in confluent cultures of RE and BICR/M1R-K cells for medium with a high $\mathrm{K}^{+}$concentration (see table 1) which resulted in a permanent low P.D. Preliminary findings indicate that the proliferation rate is of the same order after this medium exchange as after an exchange for EagleDulbecco or HEPES medium.

\section{Ionic coupling and culture conditions}

For some representative cell lines, namely BICR/M1R-K, RE, RE-F and HeLa, we investigated ionic coupling both in calf serum and fetal calf serum medium. The results obtained with fetal calf serum were not different from those described for cells in calf serum medium: fibroblastoid cells were ionically coupled, whereas epithelioid cells had no coupling. Similar results were obtained when the influence of medium conditioned by coupled cells was tested on noncoupled cells and vice versa. The medium of a $24 \mathrm{~h}$ culture of $\mathrm{RE}$ cells was changed for medium of a similar culture of BICR/M1R-K cells. No coupling was observed within $70 \mathrm{~h}$. The coupling of BICR/M1R-K cells was unaffected within the same time when grown in conditioned medium of the non-coupled RE cells. In mixed cultures of RE and RE-F cells, which were selected from the RE cells, ionic coupling was found between fibroblastoid cells as long as they were not separated by epithelioid cells. A single epithelioid 
RE cell between fibroblastoid RE-F cells was sufficient to prevent any ionic coupling, as was observed on several occasions (15 cases).

Cultures of RE-F, RE and BICR/M1R-K cells, passaged by shaking the monolayer, showed that neither ionic coupling nor potential difference were influenced by the use of trypsin for passaging.

\section{Ionic coupling and cell cycle}

In most cell cultures one can observe synchronously proliferating areas which are characterized by a higher proportion of mitotic cells. Furthermore, in autoradiograms of ${ }^{3} \mathrm{H}$-thymidine-labelled cultures most of the labelled cells are often found in particular areas. This phenomenon of local synchrony was observed in autoradiograms of BICR/M1R-K and HeLa cells [15] and RE cells [11].

The variation of the communication ratio mentioned before, may have been caused by measuring coupling between cells in different phases of the cell cycle. Therefore, we partially synchronized monolayer cultures of both coupled (BICR/M1R-K) and non-coupled (RE) cells by blocking their passage through the cell cycle at the G1/S boundary with hydroxyurea and in mitosis with Colcemid. After releasing the cells from the block by medium exchange, we measured ionic coupling and P.D.s in these cultures for periods of up to $40 \mathrm{~h}$. At no time could significant differences to non-synchronized cultures be detected, i.e., the variation of the ionic coupling was the same in the BICR/M1R-K cells, whereas in the RE cells no ionic coupling could be detected. In both cell lines the P.D. was about $50 \mathrm{mV}$ over this period of time. The presence of hydroxyurea or Colcemid in the medium did not influence the P.D. or ionic coupling of the cells.

\section{Ionic coupling and tumorigenicity}

As already shown in table 2, cells of both normal and malignant origin are ionically coupled if they appear fibroblastoid and are not coupled if they appear epithelioid. The investigated cells of normal origin may, however, have undergone malignant transformation in culture. The investigation of tumorigenicity is complicated by the fact that cells cultured to different densities may differ in their ability to produce tumors [1]. The tumorigenicity stated in the literature may, therefore, not be reliable for the cell lines we investigated, whereas those cited as "personal communication" were made with the same cell lines used for the electrophysiological investigations.

RE, RE-F and BICR/M1R-K cells were checked parallel with the in vitro electrophysiological investigations. Eight Sprague Dawley baby rats were injected with $1 \times 10^{6}$ RE cells each and 5 such rats with $1 \times 10^{6}$ RE-F cells. Neither the epithelioid [12] nor the fibroblastoid embryonic rat cells gave rise to a tumor within 12 months. On the other hand the BICR/M1R-K cells, which were derived from a mammary tumor of the Marshall rat [31], gave rise to tumors in all 7 Marshall baby rats within 10 days, when injected in the same way. The saturation density of these 3 cell lines in culture was of the order of $2 \times 10^{5}$ cells $/ \mathrm{cm}^{2}$.

\section{DISCUSSION}

The results presented in this paper indicate that the ionic coupling of the established cell lines investigated is in some way connected with their morphology: fibroblastoid cells are ionically coupled; epithelioid cells are not. Furthermore, the presence or absence of ionic coupling between these non-excitable cells does not seem to be connected with malignant or normal growth or with the 
origin of the cells. Fibroblastoid cells derived from primary or transplanted tumors possessed ionic coupling as did cells that were derived from normal tissue. Cells that gave rise to tumors in the respective baby animals showed no difference in ionic coupling to those cells that did not produce tumors. All investigated epithelioid cell lines were noncoupled, again regardless of their origin and tumorigenicity.

A recent hypothesis advanced by Loewenstein and co-workers [2, 6, 20, 21] implying that non-coupled cells are potentially cancerous, whereas coupled cells can be either normal or cancerous, cannot be proved or disproved as long as no definite criterion exists for a cellular 'potential for malignancy'. We therefore applied the same tumorigenicity test as these authors [2] with the modification that 10 -day-old isogeneic rats were used, since animals of this age would be expected to show the malignant behaviour of implanted cells even better than adult animals. Nevertheless, it is of course possible that the epithelioid RE cells, for instance, possess a 'potential for malignancy' which we were unable to demonstrate. This restriction, however, also applies to tumorigenicity tests of ionically coupled cells. Considering the numerous examples of coupled malignant cell lines $[5,6,13,17,18$, 39] together with the present impossibility to recognise a cell as 'potentially cancerous', we believe that ionic coupling cannot be used as a criterion to distinguish between normal and malignant cells.

The definition of fibroblastoid versus epithelioid morphology is not generally agreed upon and its association with a well defined measurable phenomenon, such as ionic coupling remains unsatisfactory as it bears the risk of a circular proof. However, the connection between ionic coupling and cell morphology in permanent cell lines is also contained in the experimental data of several publications $[2,6,13,14,25]$, where the cell morphology was not determined with regard to our proposed relation.

Loewenstein and co-workers $[2,6]$ have clearly described a different ionic coupling of permanent epithelioid and fibroblastoid cells. However, they explain their results with their above-mentioned hypothesis.

It was shown by Furshpan \& Potter [13] in 1968 that the ionic coupling between virustransformed cells could not be distinguished from that of the non-transformed parent line. These authors also found that cells derived from the Crocker mouse sarcoma were ionically coupled. All their lines were cells of fibroblastoid morphology; epithelioid cells were not investigated.

An exception to the reported difference between fibroblastoid and epithelioid cells can be found in a publication of Gilula and co-workers [14]. They described cells of an L line (A9) as 'fibroblastic' which were not ionically coupled either to cells of the same type or to cells of other coupled lines. The question arises whether these A9 cells are fibroblastoid when forming a confluent monolayer, the situation which we used for the determination of cell morphology, or if they form an epithelioid monolayer, as is the case with other L lines [34]. The two other fibroblastoid cell lines investigated by these authors were ionically coupled. It should be clearly statcd that the conncetion of epithelioid morphology with the absence of coupling is only true for established cell lines, not for primary or secondary cultures. Established heteroploid cell lines are in a dedifferentiated state, which may account for the described membrane properties. Cultured diploid cells which are differentiated with regard to the production of certain tissue or organ specific proteins [8, 38, see 2] must not necessarily show these membrane 
properties associated with the morphology.

The already reported faint ionic coupling of HeLa and KB cells [16] was probably due to the demonstrated blebs which sometimes develop after insertion of the electrodes. These blebs can be more clearly seen at the border of a group of cells (fig. 4) than in a dense monolayer. To avoid this artifact, ionic coupling was considered to be present only when detected between cells separated by one or more other cells. These blebs may be enveloped by a membrane with different properties from that of the original cell, thus enabling coupling between cells which normally possess no low-resistance junctions.

True non-coupling is not easily demonstrated since the absence of a coupling pulse can also be due to uncoupling of the cells by electrode insertion. To avoid this possible uncoupling we measured the membrane resistance using just one electrode, so reducing the likelihood of artificial uncoupling. This provides an indication of whether or not low-resistance junctions are present. Non-coupled cells have a similar ohmic membrane resistance if they are isolated or in contact with each other. Isolated coupled cells have an ohmic membrane resistance of the same order as non-coupled cells, but as soon as they are in contact with each other, their resistance decreases in relation to the amount that their surface area increases. As these cells are interconnected with low resistance junctions, the amount of surface membrane by which the current can pass into the medium has a considerable effect on the measured resistance. If the surface membrane doubles, the resistance should be halved. It can be clearly seen from table 3 that coupled fibroblastoid cells have a lower resistance when in contact with each other than non-coupled cells. Thus, three independent experiments indicate that artificial uncoupling was very unlikely to occur in the epithelioid cell lines: the impossibility to detect ionic coupling when fibroblastoid RE-F cells were separated by a single epithelioid RE cell, the measurements of the membrane resistances using a single electrode and, furthermore, the negligible influence on the coupling pulse in fibroblastoid cells, when the medium was exchanged during insertion of three electrodes, which shows the stability of the low-resistance junctions.

A phenomenon observed in all investigated cell lines, regardless of their morphology, was the low P.D. in single isolated cells and the high P.D. in cells of a monolayer as already described $[16,32]$. This seemed to indicate that the P.D. may be connected with the proliferative activity of the cells. However, medium exchange in a dense monolayer culture of non-coupled cells for a high $\mathrm{K}^{+}$medium which resulted in a low P.D. of about $17 \mathrm{mV}$ in all cells, caused the same proliferation rate as that observed after exchanging for fresh media with a normal $\mathrm{K}^{+}$ concentration (Eagle-Dulbecco or HEPES medium). Furthermore, stimulation of cell proliferation after exchange for medium containing fresh serum and at optimum $\mathrm{pH}$ has been described for several cell lines and different media $[9,23,28,35,41]$. These findings suggest that proliferation is not linked to the P.D. of the cells which was regarded as a regulating mechanism by Cone [7].

The different P.D. measurements of single isolated mitotic and interphase cells seemed to indicate a relationship between the P.D. and the cell cycle. However, in partially synchronized monolayers this correlation could not be confirmed. Furthermore, experiments also revealed that in fibroblastoid cells ionic coupling does not vary with the cell cycle position of the cells.

The height of the P.D. also had no in- 
fluence on the ionic coupling between fibroblastoid cells. Fibroblastoid cells depolarized by decreasing the bicarbonate concentration of the medium [16] had a P.D. of about 35 $\mathrm{mV}$, but were ionically coupled in the same way as in normal medium where the P.D. is about $50 \mathrm{mV}$. Exchanging normal medium against bicarbonate-free salt-glucose solution while measuring the ionic coupling, showed that the communication ratio could vary during this procedure, but with no preferred direction. The same change in the communication ratio would be observed, whether the pulse varied in either of the impaled cells. All possible variations of the communication ratio were observed during these exchanging experiments. These were interpreted as being caused by the streaming of medium, resulting in slight movements of the electrodes and, therefore, also of the cells, which might be expected to influence the junctions between cells as well as the membrane permeability.

As was suggested by Weiss [42], the lowresistance junctions which allow ionic coupling could be lysed by enzymes released from the cells. Our experiments show that medium conditioned by a non-coupled cell line was unable to interrupt the junctions in a coupled cell line. This could be due to the specificity of such enzymes, but co-cultivation of both coupled and non-coupled embryonic rat cells of the same origin did not result in a breakdown of the junctions in the coupled cells. These low-resistance junctions which are reported to be gap junctions $[14,19$, $26,27,33]$ seem to involve special membrane molecules which are not specific for one cell line, since coupled cells of different cell lines have been found coupled together [2, 14, 24]. Our findings on the depolarisation of coupled cells by low-bicarbonate medium, also indicated common membrane properties in each of the two morphological classes of cells. Electronmicroscopic investigations should show if the appearance of gap junctions is associated with fibroblastoid morphology. Using the reversible transformation of epithelioid cells into fibroblastoid cells by dibutyryl adenosine $3^{\prime}: 5^{\prime}$ cyclic monophosphate and testosterone, as described by Puck and co-workers [29], we are presently investigating to what extent these membrane properties are connected with the morphological appearance of the cells.

We are indebted to Professor H. Friedrich-Freksa for valuable discussion and encouragement and to Dr A. Grüneisen for carrying out the tumorigenicity tests. The technical assistance of Mrs K. Gauch and Miss I. Klein is gratefully acknowledged.

This investigation was supported by the Deutsche Forschungsgemeinschaft.

\section{REFERENCES}

1. Aaronson, S A \& Todaro, G J, Science 162 (1968) 1024.

2. Azarnia, R \& Loewenstein, W R, J membrane biol 6 (1971) 368 .

3. Baird, I, Med biol engng 5 (1967) 295.

4. Barski, G \& Belehradek, J jr, The proliferation and spread of neoplastic cells, p. 511. Williams \& Wilkins, Baltimore (1968).

5. Boitsova, L Y, Kovalev, S A, Chailakhyan, L M \& Sharovskaya Y Y, Tsitologiya 12 (1970) 1255

6. Borek, C, Higashino, $\mathrm{S} \&$ \& Loewenstein, W R, J membrane biol 1 (1969) 274.

7. Cone, C D, Trans NY acad sci ser II 31 (1969) 404.

8. Coon, H G, J cell biol 39 (1968) 29a.

9. Eagle, H, Science 174 (1971) 500.

10. Fabricius, H A. Personal communication.

11. Frank, W. Personal communication.

12. Frank, W, Ristow, H-J \& Schwalb, S, Exptl cell res 70 (1972) 390.

13. Furshpan, E J \& Potter, D D, Current topics in developmental biology (ed A A Moscona \& A Monroy) vol. 3, chap. 4, p. 95. Academic Press, New York, London (1968).

14. Gilula, N B, Reeves, O R \& Steinbach, A, Nature 235 (1972) 262.

15. Grüneisen, A. Personal communication.

16. Hülser, D F, Pflügers arch eur j Physiol 325 (1971) 174.

17. - Abstr symp cell hybridization and cell memhranes, 3-5 May, 1972, Jas7owiec (Poland). Eur $\mathrm{j}$ cancer. In press.

18. Hülser, D F \& Rajewsky, M F, Abstr dtsch Krebskongr p. 22. Springer-Verlag Berlin, (1971).

19. Johnson, $R$ G \& Sheridan J D, Science 174 (1971) 717. 
20. Loewenstein, W R, Canadian cancer conference. Proc 8th Canad cancer res conf 1968, Honey Harbour, Ontario (ed J F Morgan), p. 162. Pergamon Press, Toronto (1968).

21. Loewenstein, W R, Persp biol med 11 (1968) 260.

22. Loewenstein, W R \& Kanno, Y, J cell biol 33 (1967) 225.

23. Macieira-Coelho, A, Int j cancer 2 (1967) 297.

24. Michalke, W \& Loewenstein, W R, Nature 232 (197l) 121.

25. O'Lague, $\mathbf{P}$, Dalen, $\mathbf{H}$, Rubin, $\mathrm{H} \&$ Tobias, $\mathrm{C}$, Science $170(1970) 464$.

26. Pinto da Silva, P \& Gilula, N B, Exptl cell res 71 (1972) 393.

27. Pockrand, H \& Frömter, E, J membrane biol. Submitted for publication.

28. Pontén, J, Westermark, B \& Hugosson, R, Exptl cell res 58 (1969) 393.

29. Puck, T T, Waldren, C A \& Hsie, A W, Proc natl acad sci US 69 (1972) 1943.

30. Rajewsky, M F. Personal communication.

31. Rajewsky, M F \& Grüneisen, A, Eur j immunol 2 (1972) 445 .
32. Redmann, K. Abstr symp cell hybridization and cell membranes 3-5 May, 1972, Jaszowiec (Poland), Eur j cancer. In press.

33. Rose, B, J membrane biol 5 (1971) 1.

34. Rose, G G, Atlas of vertebrate cells in tissue culture. Academic Press, New York, London (1970).

35. Rubin, H, J cell biol 51 (1971) 686 .

36. Schwöbel, W. Personal communication.

37. Schwöbel, W \& Ahl, R, Arch ges Virusforsch 38 (1972) 1.

38. Shapiro, A L, Siegel, I M, Scharff, M D \& Robbins, E, Invest ophthal 8 (1969) 393.

39. Sheridan J D, J cell biol 45 (1970) 91.

40. Southam, C M, Babcock, V I \& de Masi, M, Cancer res 24 (1964) 345.

41. Todaro, G J, Lazar, G K \& Green, H, J cell comp physiol 66 (1965) 325 .

42. Weiss, L, Int j cancer 8 (1971) 546.

Received August 1, 1972

Revised version received February 12, 1973 